\title{
Radiotherapy of prostate cancer in renal transplant recipients: single-center experience
}

\author{
M. GOJDIC ${ }^{1, *}$, Z. ZILINSKA ${ }^{1}$, I. KRAJCOVICOVA², P. LUKACKO ${ }^{3}$, J. GREZDO ${ }^{4}$, B. OBSITNIK ${ }^{3}$, J. BREZA SR ${ }^{1}$, B. TREBATICKY ${ }^{1}$ \\ ${ }^{1}$ Department of Urology with Kidney Transplant Centre, Comenius University Faculty of Medicine and University Hospital Bratislava, Slovakia; \\ ${ }^{2} 1^{\text {st }}$ Department of Oncology, Comenius University Faculty of Medicine and St. Elisabeth Cancer Institute in Bratislava, Slovakia; ${ }^{3}$ Department \\ of Radiation Oncology, Slovak Medical University and St. Elisabeth Cancer Institute in Bratislava, Slovakia; ${ }^{4}$ Department of Medical Physics, \\ Slovak Medical University and St. Elisabeth Cancer Institute in Bratislava, Slovakia
}

${ }^{*}$ Correspondence: mgojdic81@gmail.com

Received May 7, 2018 / Accepted June 22, 2018

\begin{abstract}
This study analyzed the long-term outcomes of localized prostate cancer in renal transplant recipients after radiotherapy treatment - mainly brachytherapy. We retrospectively analyzed clinical data of renal transplant recipients between 2003 and 2016 at a single tertiary center, and identified four patients with high serum PSA level during regular follow-up, 1-108 months after primary renal transplantation. The mean age of patients with detected high serum PSA level with $9.25 \mu \mathrm{g} / \mathrm{l}$ median was 59.05 years. All four patients had functioning grafts. To prove prostate cancer, they underwent trans-rectal prostate biopsy, with no complications. Histological evaluation identified prostate adenocarcinoma (Gleason 6-7, stage T1-2cN0M0) in three patients. The biopsy in the fourth patient was negative and he therefore had trans-urethral prostate resection. Histological evaluation of resected prostate tissue revealed prostate adenocarcinoma (Gleason 7, 4+3). All patients began treatment with androgen deprivation therapy. Three patients were indicated for permanent prostate brachytherapy (BT) with iodine-125 $\left({ }^{125} \mathrm{I}\right)$ seeds and the trans-urethral resection patient was referred for external beam radiotherapy (EBRT). After a mean follow-up of 49 months (range, 30-73), all patients, irrespective of type of radiotherapy, were in complete clinical and biochemical remission, with undetectable PSA levels. The kidney grafts remained functional, with a mean creatinine level of $99 \mu \mathrm{mol} / \mathrm{l}$ (range 64-123) and a glomerular filtration rate of $1.17 \mathrm{ml} / \mathrm{s} / 1.73 \mathrm{~m}^{2}$ (range, 0.89-1.59). Radiation-induced late adverse effects were reported in two BT patients; one had clinically significant urine incontinency and the other suffered urethral stricture. Localized prostate tumor was identified in all reported patients, and all received radiotherapy plus androgen deprivation. All patients were disease-free at the time of the last follow-up. Therefore, combined BT and twelve months androgen deprivation appears both safe and effective for patients with prostate cancer after kidney transplantation.
\end{abstract}

Key words: kidney transplantation, radiotherapy, brachytherapy, prostate cancer

Prostate cancer (PCa) is the second most common solid malignancy in males; with recorded 54.9/100000 per year Slovak incidence in 2010 [1]. Compared with age-matched controls in the general population, transplant recipients have increased risk of a variety of malignancies due to risk factors such as patient-, transplant- and medication-related aspects. According to a recent meta-analysis by Shang et al., the pooled standardized incidence rate for $\mathrm{PCa}$ is more frequent than in the general population [2]. A Slovak multi-center analysis of cancer occurrence in renal transplant recipients revealed that PCa ranked sixth, with an incidence of 9.4\% [3].

Currently, Slovakia publishes no specific guidelines or consensus regarding prostate cancer screening in patients after kidney transplantation. However, the European Association of Urology advises use of general population guidelines, with an annual test for prostate-specific antigen (PSA) and a digital rectal exam for all male patients aged 50 years and over who have an expected life span of at least 10 years [4]. There are several possibilities for PCa management, including active surveillance, surgery and radiotherapy, with or without androgen deprivation therapy; but there is no clear evidence to suggest the best choice. Therefore, decisions on PCa treatment are highly preference-sensitive and require shared decision-making to ensure that the preference of each patient is met [5]. Management of localized PCa in renal transplant recipients is challenging because of long-term 
immuno-suppression, often using drugs and regimens that are not optimal for the patient. Consideration must also be given to possible treatment-induced injury to the transplanted kidney and ureter located in the iliac fossa. Irradiation of localized PCa is not usually an option for the general population because of the post-radiation risks which include urethal stenosis and gastrointestinal toxicity.

Trans-perineal interstitial permanent prostate brachytherapy (BT) is a minimally invasive approach to treating localized PCa, and although it also has a favourable toxicity profile there is little data on BT utility in renal transplant patients. This paper therefore analyzes the long-term outcomes of radiotherapy (mainly BT) treatment of localized prostate cancer in renal transplant recipients. Results are then discussed in co-ordination with non-systematic literature reviews.

\section{Patients and methods}

Patients. Transplant recipients were reviewed between 2003 and 2016; with 516 renal transplantations performed at a single tertiary center. Patients with cadaveric and living kidney transplants were analyzed, and all patients were followed up by transplant physicians each 6 months - and more frequently if clinically indicated. Follow-up evaluation included basic clinical examination, laboratory parameters and kidney ultrasound. All Slovak renal transplant recipients undergo annual PCa screening from 50 years of age; the tests include measurement of serum prostate-specific antigen
(PSA) levels and a digital rectal examination. Patients with elevated PSA undergo a prostate biopsy under transrectal ultrasound guidance. If $\mathrm{PCa}$ is diagnosed, a decision regarding further treatment is made by a multidisciplinary team comprising a uro-oncologist, a radiation oncologist and a transplant physician. Treatment decisions are based on the patient's particular circumstances and preferences, but they also depend on clinical staging and the patient's overall clinical condition. Following PCa diagnosis and treatment, patients were followed up every 3 months to assess clinical, biochemical and radiology signs of local recurrence or distant metastasis. All data was analyzed retrospectively; and no patients missed their follow-up procedures after diagnosis.

Radiotherapy treatment. BT implantation was performed under general anesthesia in an operating theatre. The patients were placed in the dorsal lithotomy position and the median operative time was $105 \mathrm{~min}$. Guided by trans-rectal ultrasound, and depending on prostate size, 40 to 48 radioactive $\left({ }^{125} \mathrm{I}\right)$ seeds (model BebigS17/S06), with prescribed low $145.0 \mathrm{~Gy}$ dose and single grain activity on the application day of $0.5-0.555 \mathrm{mCi}$ were injected through the perineum and into the prostate (Figure 1).

The dose rate, measured $30 \mathrm{~cm}$ ventrally from the small pelvis, was up to $1.0 \mu \mathrm{Sv} / \mathrm{h}$. All three patients recovered quickly and were discharged within 48 hours. The dose from the permanent prostate implant was delivered over several months with decreasing dosage. Although the actual radiobiological effect on the organ cannot be calculated simply, the maximum dose to the transplanted kidney was approxi-

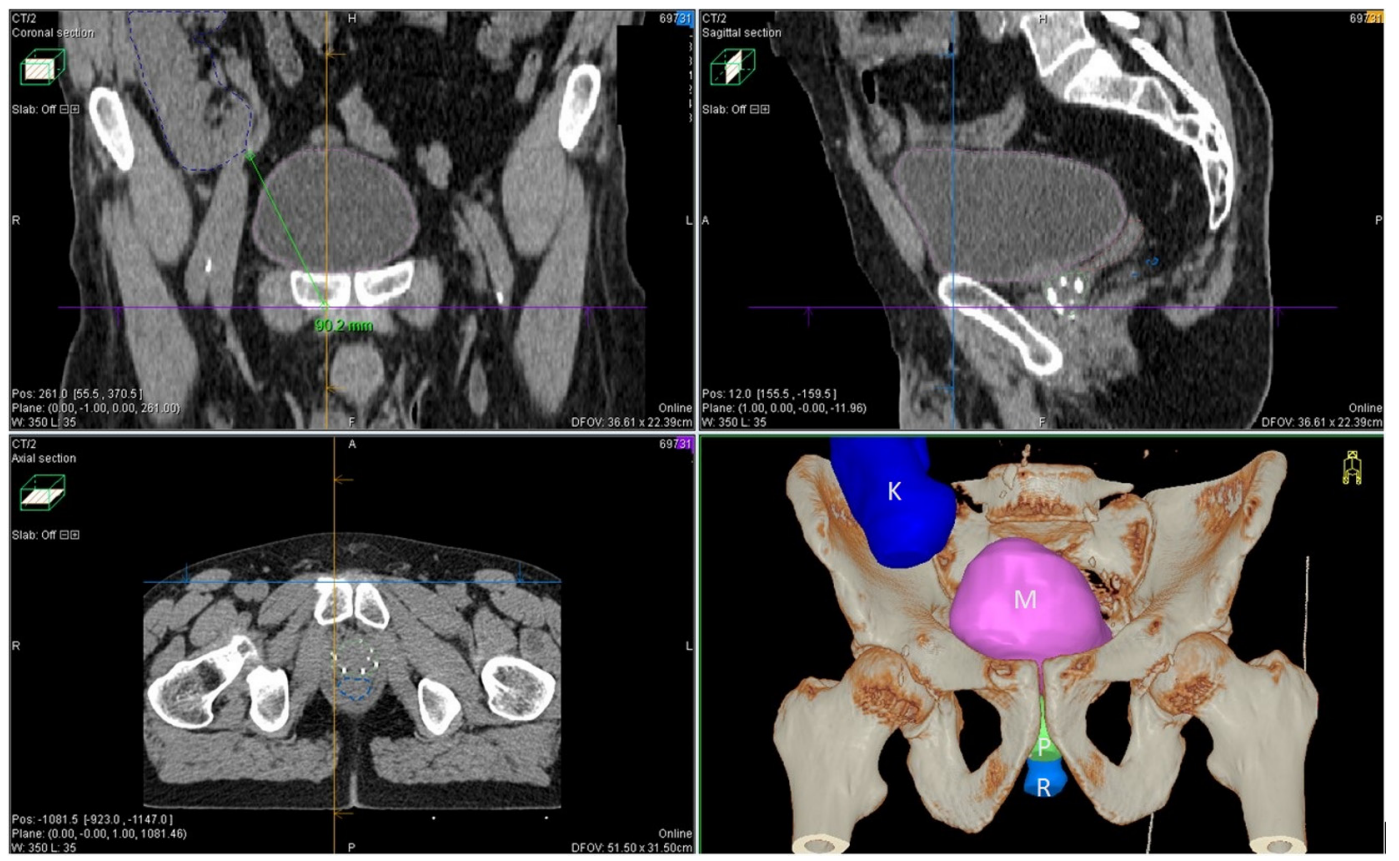

Figure 1. Orthogonal CT view of patient after kidney transplantation showing the long distance from the transplanted kidney to the prostate with permanent implantation. The 3D model showing organs: bladder $(M)$, transplanted kidney $(K)$, prostate $(P)$, and rectum $(R)$. 
mately $10.2 \%$ of the prescribed dose (145.0 Gy LDR). This was used because of the very steep gradient in the BT dose and it preserved transplanted organ function. Treatment with the LH-RH agonist continued for 1-year post-brachytherapy (BT).

Patient with contra-indications for BT due to transurethral prostate resection underwent radical external beam radiotherapy with 3D CRT (3-dimensional conformal radiotherapy), with a dose of $74 \mathrm{~Gy}$ to the prostate. The maximum dose received by the transplanted kidney was $2.33 \mathrm{~Gy}$.

\section{Results}

Four renal transplant patients (mean age, 59.05 years; range, 56.0-62.8) who underwent annual follow-up due to increased serum PSA level were identified. This occurred 1-108 months after primary renal transplantation (20112014). Immunosuppressive therapy remained unchanged after PCa diagnosis in three of these patients, and this consisted of sirolimus plus corticosteroids or a combination of tacrolimus, mycophenolate mofetil and corticosteroids. The remaining patient was switched from tacrolimus plus mycophenolate mofetil to sirolimus plus corticosteroids. No patient had previous cancer diagnosis, all had functioning grafts and we observed no change in graft function after changing medication. One patient experienced acute graft rejection 2 months after transplantation, and this was treated with rituximab combined with immunoglobulins and plasmapheresis. Table 1 lists the patients' demographic and clinical characteristics.

Despite maintenance immuno-suppressive therapy, all patients underwent a trans-rectal prostate biopsy under antibiotic prophylaxis, with no complications. Histological evaluation identified prostate adenocarcinoma (Gleason
6-7, stage $\mathrm{T} 1-2 \mathrm{cN} 0 \mathrm{M} 0)$ in three patients, and the remaining patient returned a negative PCa biopsy. Despite this, his serum PSA was elevated and he underwent trans-urethral prostate resection. Histological evaluation of the resected organ revealed incidental localized prostate adenocarcinoma (Gleason 7, 4+3).

Treatment with a luteinizing hormone-releasing hormone (LH-RH) agonist was begun in all patients and they were referred to a radiation oncologist. Three patients were referred for BT with iodine-125 $\left({ }^{125} \mathrm{I}\right)$ seeds and the patient with incidental pCa diagnosed after trans-urethral resection was referred for external beam radiotherapy (EBRT).

After a mean follow-up of 49 months (range, 30-73) from radiotherapy, seed implantation or EBRT, all patients, irrespective of type of radiotherapy, were in complete clinical and biochemical remission, with undetectable PSA level. The kidney grafts remained functional, with a mean creatinine level of $99 \mu \mathrm{mol} / \mathrm{l}$ (range, 64-123) and a glomerular filtration rate of $1.17 \mathrm{ml} / \mathrm{s} / 1.73 \mathrm{~m}^{2}$ (range, 0.89-1.59). Although there was no acute rejection from altered immunosuppressive therapy or PCa treatment, radiation-induced late adverse effects were reported by two of the BT patients. Compared with baseline measurements, one patient experienced clinically significant urgent urinary incontinence (Radiation Therapy Oncology Group (RTOG) grade 1-2) and treatment with the potent $\beta 3$-adrenoceptor agonist mirabegron was ineffective. The remaining BT patient had to undergo optic urethrectomy due to urethral stricture 30 months after BT. This may have been caused by repeated ureteroscopies before $\mathrm{CaP}$ diagnosis. Urinary function in the other two patients returned to baseline levels, and none of the four patients experienced significant baseline changes in bowel function or kidney graft injury.

Table 1. Patient demographic and clinical characteristics.

\begin{tabular}{|c|c|c|c|c|}
\hline Clinical characteristics & Patient 1 & Patient 2 & Patient 3 & Patient 4 \\
\hline Age at the time of PCa diagnosis (years) & 56.0 & 57.8 & 62.8 & 59.6 \\
\hline Time after renal transplantation (months) & 108 & 6 & 1 & 38 \\
\hline Type of graft donor & Living unrelated & Deceased & Deceased & Deceased \\
\hline Aetiology of kidney failure & unknown & TIN & TIN & FSGS \\
\hline Type of dialysis & Hemo & Hemo & Hemo & Hemo \\
\hline Time of dialysis (months) & 3 & 21 & 15 & 36 \\
\hline Gleason score & $6(3+3)$ & $6(3+3)$ & $7(4+3)$ & $6(3+3)$ \\
\hline Clinical stage & T1cN0M0 & T2cN0M0 & $\mathrm{T} 2 \mathrm{cN} 0 \mathrm{M} 0$ & $\mathrm{~T} 2 \mathrm{cN} 0 \mathrm{M} 0$ \\
\hline PSA at the diagnosis $(\mu \mathrm{g} / \mathrm{l})$ & 8.94 & 12.24 & 7.82 & 9.55 \\
\hline Immunosuppression at the time of PCa diagnosis & $\mathrm{SIR}+\mathrm{KS}$ & TAC+MMF & $\mathrm{TAC}+\mathrm{MMF}+\mathrm{KS}$ & $\mathrm{TAC}+\mathrm{MMF}+\mathrm{KS}$ \\
\hline Immunosuppression after diagnosis of PCa & $\mathrm{SIR}+\mathrm{KS}$ & SIR+KS & $\mathrm{TAC}+\mathrm{MMF}+\mathrm{KS}$ & $\mathrm{TAC}+\mathrm{MMF}+\mathrm{KS}$ \\
\hline Type of radiotherapy & BT & BT & EBRT & BT \\
\hline Androgen deprivation therapy & Yes & Yes & Yes & yes \\
\hline
\end{tabular}

$\mathrm{PCa}=$ prostate cancer; $\mathrm{PSA}=$ prostate specific antigen; $\mathrm{TIN}=$ tubuloinerstitial nephritis; $\mathrm{FSGS}=$ focal segmental glomerulosclerosis; $\mathrm{SIR}=$ sirolimus; $\mathrm{TAC}=$ tacrolimus; KS= corticosteroids; $\mathrm{MMF}=$ mycophenolate mofetil; $\mathrm{BT}=$ brachytherapy; $\mathrm{EBRT}=$ external beam radiotherapy 


\section{Discussion}

Treatment of PCa in renal transplant recipients is quite challenging because of the anatomical and clinical management-related issues; including the position of the graft in the iliac fossa, immunosuppression to prevent graft rejection and a lack of knowledge of natural cancer history.

This study at a single transplant center in Slovakia reports our experience of combined radiotherapy and androgen deprivation as $\mathrm{PCa}$ treatment in renal transplant recipients. In general, individuals diagnosed with PCa receive BT because this treatment has excellent long-term outcomes, including a high level of local disease control, high rates of disease-free survival, low invasiveness and a low incidence of acute and late toxicity [6].

A recent review of treatment approaches in renal transplant recipients with diagnosed PCa reports that the most frequent treatment is surgery $(\mathrm{n}=186)$, with overall survival rates of $96.8 \%$ [7]. Further, only 20 renal transplant recipients with $\mathrm{PCa}$ undergoing brachytherapy treatment have been reported in the literature (Table 2); and all as solo therapy [8-12]. Herein, we report our experience with four patients diagnosed with $\mathrm{PCa}$ after renal transplantation and undergoing radiotherapy treatment (three had BT and one had external beam radiotherapy).

Because kidneys are inherently radiosensitive (even to modest doses), there are potential problems specific to renal transplant recipients; these include radiation nephritis and ureteric strictures [13]. Dosage for prostate BT with ${ }^{125} \mathrm{I}$ drops off rapidly at approximately $2.5 \mathrm{~cm}$ distance from the prescribed $100 \%$ isodose to $10 \%$. Only $1 \%$ of the prescribed dose is detectable at a distance of $6.0 \mathrm{~cm}$. The calculated maximum dose received by the transplanted kidney after BT ranged from $0.1-0.2 \%$ of the prescribed dose of LDR BT due to the low dose rate (several months of radiation and radio-biologically negligible), whereas that after external radiotherapy was 2.33 Gy. The survival rate of all patients undergoing BT, in both our study and others, is $100 \%$. We also experienced no graft loss or changes in renal function after PCa treatment, and this is supported by other studies.

Although immuno-suppression has been implicated in malignant cell growth, it is uncertain if prostate cancer runs a more aggressive course in renal transplant recipients [12], but androgen deprivation therapy also has a crucial role in the radio-therapeutic management of intermediate- and high-risk PCa [13]. To our knowledge, this is the first study that focuses on a series of kidney transplant patients with prostate cancer treated with a combination of radiotherapy, either EBRT or BT, and androgen deprivation therapy (delivered over 12 months), which resulted in long-term prostate cancer clinical remission.

Several phase 3 randomized trials showed that combined treatment increases overall survival of patients with locally advanced disease compared to radiation therapy alone. The European Organization for Research and Treatment of Cancer found that $74 \%$ of surviving patients in the combined treatment group were free of disease after 5 years compared with $40 \%$ in the radiation only group ( $\mathrm{p}=0.001$ ) [14]. Pilepich et al. then performed trialed androgen suppression therapy and found that it improved overall survival in the combined androgen deprivation and radiotherapy group, with an estimated 10 -year absolute survival rate of $53 \%$ versus $38 \%$ for the radiation only group $(p=0.004)$ [15]. In contrast, it is long accepted that androgen deprivation therapy in patients with PCa can have side effects; including reduced libido, impotence, decreased lean body mass, increased fat mass, increased insulin resistance, and osteoporosis $[16,17]$. It is most important then to minimize morbidity by exercising caution when prescribing androgen suppression with radiotherapy; particularly in older men and those with cardiovascular disease. While we analyzed all patients who had renal transplantation at our center between 2003 and 2016

Table 2. Brachytherapy treatment of prostate cancer in the literature.

\begin{tabular}{|c|c|c|c|c|c|c|c|c|c|}
\hline Study & Pts & $\begin{array}{c}\text { Age } \\
\left(\text { years) }{ }^{a}\right.\end{array}$ & $\begin{array}{c}\text { Time } \\
\text { after } \mathrm{Tx}^{\mathrm{b}} \\
\text { (months) }\end{array}$ & Gleason & $\begin{array}{l}\text { Clinical } \\
\text { stage }\end{array}$ & $\begin{array}{c}\text { Mean } \\
\text { follow up } \\
\text { (months) }\end{array}$ & Adverse events & BR & GF \\
\hline Pettenati et al. 2016 [8] & 3 & $69.33 \pm 1.25$ & $15(12-134)$ & $6(n=3)$ & $\begin{array}{l}\text { T1c }(n=1) \\
\text { T2a }(n=2)\end{array}$ & 47 & $\begin{array}{l}\text { one patient voiding symptoms } \\
12 \text { months after BT }\end{array}$ & free & No alteration \\
\hline Beydoun et al. 2014 [9] & 4 & $64(61-66)^{c}$ & $13(6-17)$ & $\begin{array}{l}7(n=3) \\
8(n=1)\end{array}$ & $\begin{array}{l}\mathrm{T} 1 \mathrm{c}(\mathrm{n}=3) \\
\mathrm{T} 2 \mathrm{a}(\mathrm{n}=1)\end{array}$ & 44 & no & free & No alteration \\
\hline Coombs et al. 2012 [10] & 3 & $62.53 \pm 7.41$ & $10(5-28)$ & $\begin{array}{l}7(n=2) \\
6(n=1)\end{array}$ & Not clear & 90 & no & free & No alteration \\
\hline Iizuka et al. 2016 [11] & 2 & $62.5 \pm 8.5$ & $16(4-26)$ & $\begin{array}{l}6(n=1) \\
9(n=1)\end{array}$ & $\mathrm{T} 1 \mathrm{c}(\mathrm{n}=2)$ & 45 & no & free & No alteration \\
\hline $\begin{array}{l}\text { Rivero-Belenchon et al. } \\
2018 \text { [12] }\end{array}$ & 8 & $64.4 \pm 7.5$ & $6.6 \pm 6.1^{\mathrm{a}}$ & $6(n=8)$ & $\begin{array}{l}\mathrm{T} 1 \mathrm{c}(\mathrm{n}=7) \\
\mathrm{T} 2 \mathrm{a}(\mathrm{n}=1)\end{array}$ & 48 & no & free & No alteration \\
\hline
\end{tabular}

Pts - number of patients, Time after Tx - time after renal transplantation, BR - biochemical recurrence, GF - graft function, ${ }^{\mathrm{a}} \mathrm{mean} \pm \mathrm{SD}$, ${ }^{\mathrm{b}} \mathrm{mean}(\mathrm{range})$, 'median (range) 
$(\mathrm{n}=516)$ and included all patients with diagnosed prostate cancer, we acknowledge the limited sample size of the study cohort. The number of included patients also prohibited a priory calculation of the sample size necessary to yield sufficient statistical power.

In conclusion, all reported patients presented with localized tumors and received radiotherapy plus androgen deprivation. All were disease-free at the time of the last available follow-up. Therefore, combined BT and twelve months androgen deprivation appears both safe and effective for patients following kidney transplantation.

\section{References}

[1] SAFAEI-DIBA C, HLAVA P (Eds.). Cancer incidence in the Slovak Republic 2010. NHIC, Bratislava 2017; p. 188. ISBN 978-80-89292-55-4

[2] SHANG W, HUANG L, LI L, LI X, ZENG R et al. Cancer risk in patients receiving renal replacement therapy: a metaanalysis of cohort studies. Mol Clin Oncol 2016; 5: 315-325. http://doi.org/10.3892/mco.2016.952

[3] ZILINSKA Z, SERSENOVA M, CHRASTINA M, BREZA $\mathrm{J}$ SR, BENA L et al. Occurrence of malignancies after kidney transplantation in adults: Slovak multicenter experience. Neoplasma 2017; 64: 311-317. http://doi.org/10.4149/ neo_2017_220

[4] KARAM G, KÄLBLE T, ALCARAZ A, AKI FT, BUDDE K et al. Guidelines on renal transplantation. European Association of Urology 2014, p 88. http://uroweb.org/wp-content/ uploads/27-Renal-Transplant_LRV2-May-13th-2014-1.pdf. [accessed 22-06-2018]

[5] XIONG T, TURNER RM, WEI Y, NEAL DE, LYRATZOPOULOS $\mathrm{G}$ et al. Comparative efficacy and safety of treatments for localised prostate cancer: an application of network meta-analysis. BMJ Open 2014; 4: e004285. http://doi. org/10.1136/bmjopen-2013-004285

[6] GRIMM P, BILLIET I, BOSTWICK D, DICKER AP, FRANK $S$ et al. Comparative analysis of prostate-specific antigen free survival outcomes for patients with low, intermediate and high risk prostate cancer treatment by radical therapy. Results from the Prostate Cancer Results Study Group. BJU Int 2012; 109 Suppl 1: 22-29. http://doi.org/10.1111/j.1464410X.2011.10827.x

[7] MARRA G, DALMASSO E, ANGELLO M, MUNEGATO S, BOSIO A et al. Prostate cancer treatment in renal transplant recipients: a systematic review. BJU Int 2018; 121: 327-344. http://doi.org/10.1111/bju.14018

[8] PETTENATI C, JANNOT A-S, HUREL S, VERKARRE V, KREIS $\mathrm{H}$ et al. Prostate cancer characteristics and outcome in renal transplant recipients: results from a contemporary single center study. Clin Transplant 2016; 30: 964-971. http://doi.org/10.1111/ctr.12773
[9] BEYDOUN N, BUCCI J, MALOUF D. Iodine-125 prostate seed brachytherapy in renal transplant recipients: an analysis of oncological outcomes and toxicity profile. J Contemp Brachytherapy 2014; 6: 15-20. http://doi.org/10.5114/ jcb.2014.40769

[10] COOMBS CC, HERTZFELD K, BARRETT W. Outcomes in Transplant Patients Undergoing Brachytherapy for Prostate Cancer. Am J Clin Oncol 2012; 35: 40-44. http://doi. org/10.1097/COC.0b013e31820059b6

[11] IIZUKA J, HASHIMOTO Y, HASHIMOTO Y, KONDO T, TAKAGI $\mathrm{T}$ et al. Efficacy and feasibility of low-dose rate brachytherapy for prostate cancer in renal transplant recipients. Transplant Proc 2016; 48: 910-913. http://doi. org/10.1016/j.transproceed.2016.01.031

[12] RIVERO-BELENCHON I, OSMAN-GARCIA I, CONGREGADO-RUIZ CB, CABRERA-ROLDAN P, JIMENEZTORRES MJ et al. Low-dose-rate brachytherapy for prostate cancer in renal transplant recipients. Brachytherapy 2018; 17: 808-815. http://doi.org/10.1016/j.brachy.2018.06.001

[13] MARKS LB, YORKE ED, JACKSON A, TEN HAKEN RK, CONSTINE LS et al. Use of normal tissue complication probability models in the clinic. Int J Radiat Oncol Biol Phys 2010; 76: S10-S19. http://doi.org/10.1016/j.ijrobp.2009.07.1754

[14] BUSTAMI RT, OJO AO, WOLFE RA, MERION RM, BENNETT WM et al. Immunosuppression and the risk of posttransplant malignancy among cadaveric first kidney transplant recipients. Am J Transplant 2004; 4: 87-93. https://doi. org/10.1046/j.1600-6135.2003.00274.x

[15] PISANSKY TM. Use of neoadjuvant and adjuvant therapy to prevent or delay ecurrence of prostate cancer in patients undergoing radiation treatment for prostate cancer. Urology 2003; 62: 36-45. https://doi.org/10.1016/j.urology.2003.08.004

[16] BOLLA M, COLLETTE L, BLANK L, WARDE P, DUBOIS JB et al. Long-term results with immediate androgen suppression and external irradiation in patients with locally advanced prostate cancer (an EORTC study): a phase III randomised trial. Lancet 2002; 360: 103-106. https://doi. org/10.1016/S0140-6736(02)09408-4

[17] PILEPICH M, WINTER K, LAWTON C, KRISCH RE, WOLKOV $\mathrm{H}$ et al. editors. Androgen suppression adjuvant to definitive radiotherapy in prostate carcinoma--longterm results of phase III RTOG 85-31. Int J Radiat Oncol Biol Phys 2005; 61: 1285-1290. http://doi.org/10.1016/j. ijrobp.2004.08.047

[18] AHMADI H, DANESHMAND S. Androgen deprivation therapy for prostate cancer: long-term safety and patient outcomes. Patient Relat Outcome Meas 2014; 5: 63-70. http:// doi.org/10.2147/PROM.S52788

[19] ZIARAN S, GONCALVES FM, BREZA J SR. Patients with prostate cancer treated by ADT have significantly higher fibrinogenemia than healthy control. World J Urol 2013; 31: 289-292. http://doi.org/10.1007/s00345-012-0926-x 